\title{
The changing epidemiology of hepatitis B in Greece
}

\author{
Eirini I. Rigopoulou, Nikolaos K. Gatselis, Konstantinos Galanis, Vasiliki Lygoura, Stella Gabeta, \\ Kalliopi Zachou, George N. Dalekos
}

General University Hospital of Larissa, Greece

\section{Abstract}

\section{Introduction}

Reports during the preceding decades have highlighted a decline in the worldwide prevalence of hepatitis B virus (HBV)

Department of Medicine and Research Laboratory of Internal Medicine, National Expertise Center of Greece in Autoimmune Liver Diseases, General University Hospital of Larissa, Greece

Conflict of Interest: None

Correspondence to: George N. Dalekos, MD, PhD, Department of Medicine and Research Laboratory of Internal Medicine, National Expertise Center of Greece in Autoimmune Liver Diseases, General University Hospital of Larissa, Mezourlo, 41110 Larissa, Greece,

e-mail: georgedalekos@gmail.com

Received 25 September 2020; accepted: 4 January 2021; published online 26 February 2021

This work was presented as an oral e-poster (no 0127) at the $18^{\text {th }}$ European Congress of Internal Medicine, 29-31 August 2019, Lisbon, Portugal

DOI: https://doi.org/10.20524/aog.2021.0614 infection in many parts of the world [1]. Associated factors are the general improvement in socioeconomic status, the implementation of universal vaccination against HBV in highprevalence countries and successful antiviral treatment [1]. However, migration waves during the last 15 years from highmedium to low endemicity countries have contributed towards substantial changes in HBV epidemiology in recent years [2].

$\mathrm{HBV}$ prevalence, as assessed by the presence of hepatitis B surface antigen (HBsAg), is estimated to be $3.6 \%$, though there is significant variation between low $(<2 \%)$ and high $(>8 \%)$ endemicity areas [3]. Still, HBV remains a significant public health problem with a high disease burden, as evidenced by a rise in HBV-related cirrhosis and/or hepatocellular carcinoma (HCC) between 1990 and 2013 [4].

Greece is nowadays classified as a low-endemicity country for HBV, based on an estimated prevalence of $1.74 \%$ (corrected $1.88 \%$ ) [5]. However, estimation of HBV prevalence in Greece remains a difficult task, considering the vast differences between neighboring regions and between groups with diverse characteristics [6-11]. We have previously shown an HBV prevalence of $4.2 \%$ in the general population of Central Greece 
between 1999 and 2004, with cluster areas for HBV inside this region [12].

These data underscore the need to assess the epidemiology of HBV in large-scale studies, contributing towards highlighting the magnitude of the disease and assisting in developing specific prevention and control strategies, including infant vaccination, prevention of mother-to-child transmission, population-wide testing and treatment [13-15].

Accordingly, our aim was to study the epidemiological characteristics and progression of $\mathrm{HBV}$ infection in a large consecutive cohort of chronic HBV patients. We focused on identifying risk factors related to disease progression to cirrhosis, decompensation, HCC development and liverrelated death. In addition, we wanted to draw attention to areas with high HBV prevalence and to temporal trends in the epidemiological disease characteristics spanning a period of 18 years in the region of Thessaly.

\section{Patients and methods}

\section{Patients}

We prospectively analyzed data from 1910 consecutive patients with chronic HBV infection followed at the Department of Medicine and Research Laboratory of Internal Medicine, General University Hospital of Larissa, during an 18-year period (1 January 1999 to 31 December 2016; mean follow up $7.3 \pm 4.6$ years). Patients with chronic infection and chronic hepatitis were followed every 12 and 6 months, respectively, with relevant laboratory and imaging tests, while patients with cirrhosis (with or without HCC) were evaluated more frequently, according to individual requirements (every 3-6 months). The compliance of the studied population, especially of patients with chronic hepatitis or cirrhosis, was substantially good, irrespective of patients' educational level (data not shown).

The diagnosis of HBV infection was based on established international criteria [16,17]. Specifically, patients were classified according to the new nomenclature into the following categories: $\mathrm{HBV}$ e antigen (HBeAg)-positive chronic $\mathrm{HBV}$ infection, $\mathrm{HBeAg}$-positive chronic hepatitis $\mathrm{B}$ (CHB), HBeAg-negative chronic HBV infection and HBeAgnegative $\mathrm{CHB}[16,17]$. All patients were also tested for antibodies against hepatitis D virus (HDV). All patients tested negative for antibodies against hepatitis $C$ virus and human immunodeficiency virus. The diagnosis of HCC was based on well-established criteria $[16,18]$.

Data on the following parameters was collected: demographic characteristics (sex, ethnicity, place of ancestry and place of residency, educational level), reasons for initial $\mathrm{HBV}$ testing, clinical characteristics of $\mathrm{HBV}$ infection including mode of clinical presentation (acute or chronic), phase in the natural history of $\mathrm{HBV}$, presence of cirrhosis and/or HCC at presentation, mode of transmission and risk factors, daily alcohol consumption (mild: $<20 \mathrm{~g}$ and $<10$ g; moderate: $20-60 \mathrm{~g}$ and 10-40 g; and severe: $>60 \mathrm{~g}$ or $>40 \mathrm{~g}$, for men and women respectively), patients' biometrics, duration of infection and follow up. Laboratory data, including biochemistry, platelets, international normalized ratio, $\alpha$-fetoprotein, and HBV-DNA (real-time PCR -Cobas ${ }^{\circledast}$ TaqMan 48; cutoff values for detection: $6 \mathrm{IU} / \mathrm{mL}$ ), were recorded at regular time points according to established protocols.

Liver biopsy and the results of liver elastography, used as a noninvasive method for assessment of liver fibrosis, were recorded during presentation or follow-up visits. Treatment with interferon- $\alpha$ (IFN-a), pegylated-IFN-a (Peg-IFN-a) and nucleos(t)ide analogs was documented, as well as the response to treatment with these agents (biochemical, virological, virological breakthrough) $[16,17]$. Imaging results (ultrasound, computer tomography, magnetic resonance) were also recorded.

The outcomes of HBV infection, including HBsAg clearance, development of cirrhosis, decompensation of liver disease in cirrhotic patients, development of HCC, liver transplantation, and liver-related or liver-unrelated deaths were also documented.

Thessaly, located in central Greece, is one of the 13 peripheries of the country, with an estimated population of 750,000 people (census $2011 ; 6.8 \%$ of the national population). Thessaly is divided into prefectures: the prefecture of Larissa (capital city: Larissa), Magnesia including Sporades islands (capital city: Volos), Trikala (capital city: Trikala), Karditsa (capital city: Karditsa). As reported previously, we also estimated the ratio of $\mathrm{HBV}$-infected patients (either originating or residing) in each municipality by dividing the number of patients infected in the respective region by the total number of infected patients in the respective prefecture [12].

All subjects consented to participate in the study. The ethics committee of the General University Hospital of Larissa approved the study protocol (2258/21-3-2016).

\section{Statistical analysis}

Data were entered and analyzed using SPSS and Epi-Info 2002 software. Normally distributed values are expressed as mean \pm standard deviation, while non-normally distributed data are given as median and interquartile range (IQR). Data were analyzed by Student's $t$-test, $\chi^{2}$ test (two by two with Yate's correction), Fisher's exact test, Kaplan-Meier log-rank test, Cox regression analysis, binary logistic regression model, and multiple Cox regression model, where appropriate. Two-sided P-values $<0.05$ were considered as statistically significant.

\section{Results}

\section{Demographic and clinical characteristics of HBV patients}

The epidemiological, clinical and laboratory characteristics of 1910 patients with chronic HBV infection during their first assessment are presented in Table 1 . The vast majority of 
Table 1 Epidemiological, clinical and laboratory characteristics of 1910 patients with chronic hepatitis B at their first assessment

\begin{tabular}{|c|c|}
\hline Characteristics & $\mathrm{n}(\%)$ or average $\pm \mathrm{SD}$ \\
\hline Sex: M/F & $1161(60.8 \%) / 749(39.2 \%)$ \\
\hline Age (years) & $50.1 \pm 15.8$ \\
\hline Duration of infection (years) & $42.2 \pm 15.8$ \\
\hline BMI $\left(\mathrm{kg} / \mathrm{m}^{2}\right)$ & $26.6 \pm 3.4$ \\
\hline $\begin{array}{l}\text { Alcohol use } \\
\text { Yes (moderate or severe) } \\
\text { No (mild or no) }\end{array}$ & $\begin{array}{c}622(32.6 \%) \\
1288(67.4 \%)\end{array}$ \\
\hline $\begin{array}{l}\text { Source of infection } \\
\text { Vertical - intrafamilial } \\
\text { Traditional folk remedies } \\
\text { Iatrogenic (blood transfusion/ dental treatment) } \\
\text { Sexual } \\
\text { i.v. substance use } \\
\text { Professional exposure } \\
\text { Unknown }\end{array}$ & $\begin{array}{c}1085(56.8 \%) \\
328(17.2 \%) \\
133(6.9 \%) \\
57(3 \%) \\
3(0.2 \%) \\
7(0.4 \%) \\
297(15.5 \%)\end{array}$ \\
\hline $\begin{array}{l}\text { Educational level } \\
\text { Illiterate - elementary education } \\
\text { Secondary education } \\
\text { Higher education }\end{array}$ & $\begin{array}{l}1101(57.7 \%) \\
507(26.5 \%) \\
302(15.8 \%)\end{array}$ \\
\hline $\begin{array}{l}\text { Ethnicity } \\
\text { Greece } \\
\text { Albania } \\
\text { Eastern Europe or Russia } \\
\text { Africa/Germany/Pakistan }\end{array}$ & $\begin{array}{c}1731(90.6 \%) \\
153(8 \%) \\
22(1.1 \%) \\
4(0.2 \%)\end{array}$ \\
\hline $\begin{array}{l}\text { Mode of presentation/ diagnosis of HBV infection } \\
\text { Presence of symptoms } \\
\text { Acute hepatitis } \\
\text { Symptoms of chronic hepatitis } \\
\text { Asymptomatic }\end{array}$ & $\begin{array}{c}107(5.6 \%) \\
23(1.2 \%) \\
84(4.4 \%) \\
1803(94.4 \%)\end{array}$ \\
\hline $\begin{array}{l}\text { Clinical phase of HBV infection } \\
\text { Chronic infection (inactive carriers) } \\
\text { Chronic hepatitis (no cirrhosis) } \\
\text { Cirrhosis (compensated and decompensated stage) } \\
\text { Hepatocellular carcinoma }\end{array}$ & $\begin{array}{c}1314(68.8 \%) \\
415(21.7 \%) \\
116(6.1 \%) \\
65(3.4 \%)^{*}\end{array}$ \\
\hline HBeAg; pos/neg & $31(1.6 \%) / 1879(98.4 \%)$ \\
\hline HBV DNA (IU/mL) & $2.629 .644 \pm 13.291 .480$ \\
\hline Anti-HDV; pos/neg & $30(1.6 \%) / 1880(98.4 \%)$ \\
\hline $\begin{array}{l}\text { Grade of fibrosis at first liver biopsy }(\mathrm{n}=262) \\
\text { No/mild fibrosis (F0-F1) } \\
\text { Moderate fibrosis (F2) } \\
\text { Severe fibrosis (F3) } \\
\text { Cirrhosis (F4) }\end{array}$ & $\begin{array}{l}112(42.8 \%) \\
86(32.8 \%) \\
26(9.9 \%) \\
38(14.5 \%)\end{array}$ \\
\hline $\operatorname{PLT}\left(/ \mathrm{mm}^{3}\right)$ & $212256 \pm 54005$ \\
\hline INR & $1.05 \pm 0.18$ \\
\hline AST (U/L), (ULN: 40) & $46 \pm 138$ \\
\hline $\operatorname{ALT}(\mathrm{U} / \mathrm{L}),(\mathrm{ULN}: 40)$ & $61 \pm 182$ \\
\hline$\gamma \mathrm{GT}(\mathrm{U} / \mathrm{L}),(\mathrm{ULN}: 37)$ & $31 \pm 36$ \\
\hline Albumin (g/dL), (ULN: 3.5 - 5.2) & $4.4 \pm 0.5$ \\
\hline Bilirubin (mg/dL), (ULN.: 1.1) & $0.9 \pm 0.9$ \\
\hline $\operatorname{AFP}(\mathrm{ng} / \mathrm{mL}),(\mathrm{ULN}: 10)$ & $6.9 \pm 108.4$ \\
\hline
\end{tabular}

*All patients diagnosed with HCC during their first assessment had cirrhosis

$N$, number of patients in each respective group; $M$, male; F, female; BMI, body mass index; HBV, hepatitis B virus; HBeAg, hepatitis B e antigen; HBV DNA, hepatitis B virus DNA; anti-HDV, antibodies against hepatitis D virus; PLT, platelets; INR, international normalized ratio; AST, aspartate aminotransferase; ULN, upper limit of normal; ALT, alanine aminotransferase; $\gamma G T$, gamma glutamyl-transferase; AFP, alpha fetoprotein 
patients $(\mathrm{n}=1803 ; 94.4 \%)$ were asymptomatic at presentation or initial assessment, and HBV diagnosis was established either during testing of first-degree relatives of HBV patients $(n=691$; $36.2 \%)$ or during blood donation $(\mathrm{n}=378 ; 19.8 \%)$.

Almost all patients ( $\mathrm{n}=1897 ; 98.4 \%)$ were HBeAg-negative/ anti-HBe-positive and 30 (1.5\%) had HDV coinfection. At first assessment, 1314 patients (68.8\%) had chronic infection, $415(21.7 \%)$ had chronic hepatitis, 116 were cirrhotic-105 (5.5\%) with compensated and $11(0.6 \%)$ with decompensated cirrhosis-and 65 (3.4\%) had HCC (all being cirrhotic). Patients' characteristics according to disease stage are shown in Table 2.

Non-cirrhotic patients with $\mathrm{CHB}$ compared to those with chronic infection were more frequently male $(\mathrm{P}<0.001)$, with higher alcohol consumption $(\mathrm{P}<0.001)$. Patients with cirrhosis and/or HCC compared to non-cirrhotic patients with $\mathrm{CHB}$ were more likely to be males $(\mathrm{P}<0.001)$, older $(\mathrm{P}<0.001)$, with longer disease duration $(\mathrm{P}<0.001)$, and reported higher alcohol consumption ( $\mathrm{P}=0.002)$ (Table 2$)$.

\section{Distribution of HBV in the region of Thessaly}

Considering that clusters of $\mathrm{HBV}$ exist in the region of Thessaly, we estimated the geographical distribution of HBV in different municipalities based on patients' origin and residence. Amongst the $1910 \mathrm{HBV}$-infected patients, 1632 (85.4\%) originated from Thessaly, including 978 (59.9\%) from the prefecture of Larissa, 269 (16.5\%) from Karditsa, 247 (15.1\%) from Trikala, and 138 (8.5\%) from Magnesia.

After excluding the capital cities of Larissa, Karditsa, Trikala and Volos, we identified municipalities with a high $\mathrm{HBV}$ ratio. Municipalities with a high ratio of HBV patients according to their origin were the municipalities of Sofades
(15.2\%) and Palama (4.1\%) in the prefecture of Karditsa, the municipality of Kalampaka (14.6\%) in the prefecture of Trikala, the municipalities of Tyrnavos (7.6\%), Sarantaporo (7\%), and Elassona (6.4\%) in the prefecture of Larissa, and the municipality of Nea Ionia (4.4\%) in the prefecture of Magnesia. Similarly, high HBV rates were recorded in people residing in these municipalities (data not shown).

\section{Temporal trends in epidemiological and clinical characteristics}

To assess whether changes in patients' epidemiological and clinical characteristics during their first assessment might have occurred over time, we divided the study into 2 periods: the first spanning 1999-2010 and the second 2011-2016. Patients evaluated for the first time during 2011-2016 ( $\mathrm{n}=309)$ were older $(55.1 \pm 16.1$ vs. $49.2 \pm 15.6$ years; $\mathrm{P}<0.001)$ and had longer disease duration $(47 \pm 16.5$ vs. $41.3 \pm 15.6$ years; $\mathrm{P}<0.001)$ compared to patients from the period 1999-2010 $(\mathrm{n}=1601)$. During 20112016, patients with foreign nationality were more likely to have attended our department for the first time ( $16 \%$ vs. $8 \%$; $\mathrm{P}<0.001)$. In addition, during the $2011-2016$ period patients tended to have a more advanced disease stage (12.3\% vs. $8.9 \%$; $\mathrm{P}=0.085)$. There were no differences in terms of sex, history of alcohol consumption, educational level, HBeAg seropositivity and laboratory parameters between the 2 periods.

\section{Treatment of HBV infection and response to treatment}

During the whole study period, 529 of $596(88.8 \%)$ patients with $\mathrm{CHB}$ received treatment with antivirals: IFN-a, Peg-

Table 2 Characteristics of HBV patients according to the stage of chronic HBV infection

\begin{tabular}{|c|c|c|c|c|c|}
\hline Characteristics & $\begin{array}{l}\text { Chronic infection } \\
\qquad(\mathrm{n}=1314)\end{array}$ & $\begin{array}{l}\text { Chronic hepatitis non-cirrhotic } \\
\qquad(\mathrm{n}=415)\end{array}$ & $\begin{array}{l}\text { Cirrhosis/ HCC } \\
\quad(\mathrm{n}=181)\end{array}$ & P-value ${ }^{*}$ & P-value ${ }^{\dagger}$ \\
\hline \multicolumn{6}{|l|}{ Sex } \\
\hline Male & $732(55.7 \%)$ & $276(66.5 \%)$ & 153 (84.5\%) & $<0.001$ & $<0.001$ \\
\hline Female & $582(44.3 \%)$ & $139(33.5 \%)$ & $28(15.5 \%)$ & & \\
\hline Age (years) & $48.5 \pm 15.9$ & $50.1 \pm 15.5$ & $61.7 \pm 10.9$ & 0.189 & $<0.001$ \\
\hline $\begin{array}{l}\text { Duration of infection } \\
\text { (years) }\end{array}$ & $41.0 \pm 15.2$ & $41.4 \pm 16.5$ & $53.4 \pm 15.1$ & 1.000 & $<0.001$ \\
\hline \multicolumn{6}{|l|}{ Alcohol } \\
\hline Yes & $357(27.2 \%)$ & $157(37.8 \%)$ & 108 (59.7\%) & $<0.001$ & 0.002 \\
\hline No & $957(72.8 \%)$ & $258(62.2 \%)$ & $73(40.3 \%)$ & & \\
\hline \multicolumn{6}{|l|}{ Educational level } \\
\hline Illiterate/elementary & 725 (55.2\%) & $236(56.9 \%)$ & $140(77.3 \%)$ & 0.267 & $<0.001$ \\
\hline Secondary education & $376(28.6 \%)$ & $103(24.8 \%)$ & $28(15.5 \%)$ & & \\
\hline Higher education & $213(16.2 \%)$ & $76(18.3 \%)$ & $13(7.2 \%)$ & & \\
\hline \multicolumn{6}{|l|}{ Ethnicity } \\
\hline Greek & 1177 (89.6\%) & 379 (91.3\%) & 175 (96.7\%) & 0.346 & 0.029 \\
\hline Other & $137(10.4 \%)$ & $36(8.7 \%)$ & $6(3.3 \%)$ & & \\
\hline
\end{tabular}

$\mathrm{n}=$ number of patients in each respective group. ${ }^{*}$ comparison between patients with chronic infection ( $\left.\mathrm{n}=1314\right)$ and non-cirrhotic patients with chronic hepatitis $(\mathrm{n}=415)$. †comparison between non-cirrhotic patients with chronic hepatitis $(\mathrm{n}=415)$ and patients with cirrhosis and/or hepatocellular carcinoma $(\mathrm{n}=181)$

HBV, hepatitis B virus; HCC, hepatocellular carcinoma 
IFN-a, nucleos(t)ide analogs, or combination. Sixty-seven patients were not treated because of bad compliance, insurance issues, or as a result of personal decision.

Treatment with IFN-a or Peg-IFN-a was prescribed in 138 patients and response to treatment was reported in 31 (22.5\%). Five hundred sixteen patients received nucleos(t)ide analogs. During follow up, 214 of 529 patients who received some kind of treatment (40.5\%) had at least one episode of viral breakthrough and 204 (38.6\%) had at least one episode of biochemical breakthrough. During the last visit, 519 patients (98.1\%) had demonstrated a virological response to treatment.

\section{Outcome of HBV patients}

HBsAg loss occurred in 161 (8.4\%) patients. The cumulative probabilities of HBsAg loss at 5-, 10- and 15-year follow up were $3.7 \%, 9.6 \%$ and $20.4 \%$, respectively. HBsAg loss was not associated with any demographic or laboratory data, including HBV-DNA levels and also IFN-a-based treatment.

After a total follow up of $6.9 \pm 4.3$ years, none of the 1314 patients with chronic $\mathrm{HBV}$ infection progressed to $\mathrm{CHB}$ or had any liver-related events and were excluded from further analysis. The remaining 596 patients with $\mathrm{CHB}$ (with or without cirrhosis/HCC) were under follow up for 8.3 \pm 5.1 years and were further analyzed in terms of outcome and possible prognostic parameters. Of the 415 non-cirrhotic patients, 51 (12.3\%) developed cirrhosis, virological breakthrough during treatment being the only prognostic factor $(\mathrm{P}=0.004)$. The cumulative incidences of cirrhosis in the 1st, 5th, 10th and 15th years were $0.2 \%, 8.3 \%, 15.3 \%$ and $17.5 \%$, respectively.

Of the 156 patients with cirrhosis (105 at initial visit and 51 during follow up), 34 patients (21.8\%) developed symptoms related to decompensated liver disease, low albumin levels $(\mathrm{P}=0.01)$ and high alcohol consumption $(\mathrm{P}=0.05)$ being independent prognostic factors. The cumulative incidences of decompensation in the $1 \mathrm{st}, 5$ th, 10 th and 15 th years were $3.2 \%$, $12.8 \%, 24.6 \%$ and $28.2 \%$, respectively. During follow up, HCC was identified in 64 of the 531 (12.1\%) patients with CHB. Of these, 41 were cirrhotic from their first evaluation, 23 patients developed cirrhosis during follow up and 11 patients were noncirrhotic at HCC diagnosis. The cumulative incidences of HCC were $1.1 \%, 7.7 \%, 13.8 \%$ and $15.9 \%$ in the 1 st, 5 th, 10 th and 15 th years, respectively. The presence of cirrhosis $(\mathrm{P}<0.001)$ and virologic breakthrough during treatment $(\mathrm{P}=0.05)$ were independent negative predictive factors for HCC development.

Liver-related death occurred in 47 of the 531 (8.9\%) patients who had $\mathrm{CHB}$ with or without cirrhosis at baseline. The cumulative incidences of liver-related death in the 1st, 5 th, 10th and 15 th years were $1.1 \%, 5.8 \%, 9.9 \%$ and $11.4 \%$, respectively. On multivariate analysis, cirrhosis $(\mathrm{P}<0.001)$, disease duration $(\mathrm{P}=0.03)$ and low levels of albumin $(\mathrm{P}=0.001)$ were associated with liver-related death.

Patients who started follow up from 2011 and onwards had lower rates of virologic breakthrough ( 9.5 vs. $45.5 \%$; $\mathrm{P}<0.001$ ) and biochemical relapse during treatment (9.5 vs. $43.4 \%$; $\mathrm{P}<0.001)$ compared to those first evaluated and treated before
2011. In addition, fewer patients progressed to cirrhosis $(1.8 \%$ vs. $14 \% ; \mathrm{P}=0.02)$ and $\mathrm{HCC}(5.1 \%$ vs. $13.2 \% ; \mathrm{P}=0.04)$. In contrast, there were no significant differences in decompensation rates of cirrhotic patients or liver-related death.

We also performed a sub-analysis of 255 patients with $\mathrm{CHB}$ under treatment with tenofovir or entecavir (mean follow up: $6.2 \pm 2.4$ years). Patients with decompensated cirrhosis or HCC at the time of treatment initiation were excluded. HCC developed in $18(7.1 \%)$ patients during follow up (mean time: $4.7 \pm 1.9$ years), increased age $(\mathrm{P}<0.001)$, and alcohol consumption $(\mathrm{P}=0.01)$ being independent prognostic factors. The cumulative incidences of HCC development at the 2nd, $3 \mathrm{rd}, 5$ th, 7 th and 10th years after initiation of tenofovir or entecavir were $0.4 \%, 2.1 \%, 4.4 \%, 9.1 \%$, and $10.2 \%$, respectively.

\section{Discussion}

Our study, being one of the largest conducted in Greece so far, delivers important information regarding the epidemiological and clinical characteristics of HBV infection, in conjunction with their temporal changes, in a large cohort of HBV patients from Central Greece. We provide sufficient evidence to suggest that $\mathrm{CHB}$ continues to be a major public health problem in the wider region of Central Greece, while areas of high prevalence are still preserved. Another asset of our study is the homogeneity of our HBV cohort in terms of virus and host characteristics, considering that the great majority were Caucasians, originating and residing in the region of Thessaly.

Even though Greece is nowadays considered a country of low endemicity, our current data confirm and further extend those from our previous study, indicating that Thessaly remains a region with clusters of HBV infection [12]. Clusters of HBV pose a significant public health problem, as they maintain the virus transmission chain.

As previously reported, the transmission of $\mathrm{HBV}$ has been largely attributed to the intrafamilial mode, considering that two thirds of the population contracted the virus either through vertical transmission, or via intrafamilial modes [12]. Overcrowded living conditions in rural areas in Greece, where the majority of HBV clusters were identified, have been previously implicated as a risk factor for intrafamilial transmission [19]. Intrafamilial transmission of $\mathrm{HBV}$ occurs during early life, when most patients are asymptomatic during acute infection and remain asymptomatic thereafter. In fact, only $5 \%$ of our HBV population sought medical advice because of the presence of symptoms, while the vast majority were assessed during testing of first-degree relatives of $\mathrm{HBV}$ patients, volunteer blood donation, or during evaluation of asymptomatic transaminasemia and hospitalization. The mean duration of HBV infection up to diagnosis was 42 years in our population. As most of our patients were ignorant of their HBV status (data not shown), they represent a silent reservoir of the virus that could have maintained HBV circulation in the community for many years. The fact that universal vaccination was implemented in Greece in 1998 for infants and adolescents suggests that a significant part of Thessaly's population has been vulnerable to $\mathrm{HBV}$ for a long period. 
In agreement with other studies, alcohol consumption was high in our cohort and was associated with advanced disease stage and progression of liver disease during follow up towards development of complications of cirrhosis and HCC [20-22]. As existing data have highlighted the synergistic role of alcohol and HBV in HCC development, public awareness as well as education of patients with chronic liver disease about the detrimental effects of alcohol is mandatory [20-22]. The long follow-up period, spanning almost 2 decades, was one of the strengths of our study, allowing us also to highlight temporal changes related to the study population and patients' characteristics associated with HBV infection.

The doubling of the number of non-Greek HBV patients during the second study period is in line with the acceleration of immigration waves from countries of higher HBV endemicity. This has been previously highlighted in different regions of Greece. In the Epirus region, 22.2\% of Albanian migrants had serological evidence of $\mathrm{CHB}$, which declined to $11.7 \%$ in young Albanian migrants in 2010 [23,24]. In the metropolitan area of Athens, the prevalence of HBV in migrants was $15.4 \%$ compared to $0.83 \%$ in the general population, while in the north-east region of Greece HBsAg prevalence was 25\% in former USSR migrants and $12.3 \%$ in a Muslim population residing in the area $[7,25]$. This underscores the need for prioritizing systematic screening and scaling up of care services in at-risk populations, such as migrants from moderate- or high-endemicity countries [26].

Owing to the infrastructure of the health system in Greece, our center acts not only as a tertiary but also as a primary and secondary health center for the region of Thessaly $[12,27,28]$. This indicates that the volume of patients being evaluated in everyday clinical practice is significant and encompasses a variety of liver diseases. Still, we need to acknowledge that the burden of HBV infection in the region of Thessaly is underestimated in this analysis, as specific populations, including migrants arriving in Greece after 2016 and living mainly in hotspots, are not included herein. Studies from Canada have demonstrated that immigrants and refugees from East Asia have a higher possibility of dying from liver disease or developing HCC compared to the general population, contributing significantly towards a higher burden of chronic liver disease in these countries [2].

The Global Burden of Disease Study has shown that deaths due to cirrhosis with or without HCC have risen by $33 \%$ from 1990 to 2013 in CHB patients [4]. Analogously, the number of patients in our cohort who were cirrhotic or had HCC at first assessment tended to increase during the second study period, even though the percentage of patients with chronic hepatitis remained stable. From our data in a large region of Greece, we could extrapolate that HBV infection remains a major cause of disability and mortality in Greece, suggesting that there is a need for improvement of public health measures to recognize and treat the disease.

The advent of more potent antiviral treatments for $\mathrm{CHB}$ patients during the last decade has halted disease progression and further improved patients' survival, with a significant decline in HCC development [29-37]. Accordingly, our analysis revealed temporal changes in response to $\mathrm{HBV}$ treatment, as demonstrated by an $80 \%$ reduction in virological and biochemical breakthrough episodes from 2011 and onwards compared to those reported before. Hence, more effective treatment with newer antivirals was associated with a significant decline in cirrhosis progression and HCC development.

In conclusion, $\mathrm{CHB}$ continues to be a major public health problem in Greece, and in particular in the wider region of Central Greece, while areas with high prevalence are still preserved. The burden of chronic liver disease tended to rise longitudinally, as attested by the increased number of patients diagnosed with advanced disease stages over time, with high alcohol consumption being an independent prognostic factor in our cohort. There was an improvement in the natural history of HBV infection over time, associated with the use of newer and more potent antiviral drugs. Our data highlight the need for scaling-up prevention and early detection strategies in our region with an emphasis on at-risk populations and implementation of treatment where appropriate.

\section{Summary Box}

\section{What is already known:}

- The epidemiology of hepatitis B virus (HBV) infection has changed worldwide lately as a result of various factors

- However, chronic hepatitis B continues to be a major public health problem in Greece

- Epidemiological characteristics and the evolution of HBV infection after long-term follow up in large number of patients in well-characterized areas of Greece are lacking

\section{What the new findings are:}

- As in other countries, there has been an improvement in the natural history of $\mathrm{HBV}$ infection in our region, associated with the use of the newer and more potent antiviral drugs

- However, during a follow up of 18 years in a large cohort of HBV patients $(n=1910)$, the burden of chronic liver disease tended to rise longitudinally, as attested by the increased number of patients diagnosed with an advanced disease stage over time

\section{References}

1. Ott JJ, Horn J, Krause G, Mikolajczyk RT. Time trends of chronic HBV infection over prior decades - A global analysis. J Hepatol 2017;66:48-54.

2. Sharma S, Carballo M, Feld JJ, Janssen HL. Immigration and viral hepatitis. J Hepatol 2015;63:515-522.

3. Schweitzer A, Horn J, Mikolajczyk RT, Krause G, Ott JJ. Estimations 
of worldwide prevalence of chronic hepatitis B virus infection: a systematic review of data published between 1965 and 2013. Lancet 2015;386:1546-1555.

4. Stanaway JD, Flaxman AD, Naghavi M, et al. The global burden of viral hepatitis from 1990 to 2013: findings from the Global Burden of Disease Study 2013. Lancet 2016;388:1081-1088.

5. Touloumi G, Karakosta A, Sypsa V, et al; Hprolipsis Study Group. Design and development of a viral hepatitis and HIV infection screening program (Hprolipsis) for the general, Greek Roma, and migrant populations of Greece: protocol for three cross-sectional health examination surveys. JMIR Res Protoc 2020;9:e13578.

6. Dalekos GN, Zervou E, Merkouropoulos MH, Tsianos EV. Prevalence of hepatitis B and C viruses infection in chronic alcoholics with or without liver disease in Ioannina, Greece: low incidence of HCV infection. Eur J Epidemiol 1996;12:21-25.

7. Kyriakis KP, Foudoulaki LE, Papoulia EI, Sofroniadou KE. Seroprevalence of hepatitis B surface antigen (HBsAg) among firsttime and sporadic blood donors in Greece: 1991-1996. Transfus Med 2000;10:175-180.

8. Zervou EK, Dalekos GN, Boumba DS, Tsianos EV. Value of anti$\mathrm{HBc}$ screening of blood donors for prevention of HBV infection: results of a 3-year prospective study in Northwestern Greece. Transfusion 2001;41:652-658.

9. Zacharakis GH, Koskinas J, Kotsiou S, et al. Natural history of chronic HBV infection: a cohort study with up to 12 years followup in North Greece (part of the Interreg I-II/EC-project). J Med Virol 2005;77:173-179.

10. Michos A, Terzidis A, Kalampoki V, Pantelakis K, Spanos T, Petridou ET. Seroprevalence and risk factors for hepatitis A, B, and $\mathrm{C}$ among Roma and non-Roma children in a deprived area of Athens, Greece. J Med Virol 2008;80:791-797.

11. Papadakis G, Okoba NA, Nicolaou C, et al; Doctors of the World Greece. Serologic markers for HBV, HCV and HIV in immigrants visiting the Athens' polyclinic of 'Doctors of the World - Greece'. Public Health 2013;127:1045-1047.

12. Stefos A, Gatselis N, Zachou K, Rigopoulou E, Hadjichristodoulou C, Dalekos GN. Descriptive epidemiology of chronic hepatitis B by using data from a hepatitis registry in Central Greece. Eur J Intern Med 2009;20:35-43.

13. Papamichail D, Petraki I, Arkoudis C, et al. Low vaccination coverage of Greek Roma children amid economic crisis: national survey using stratified cluster sampling. Eur J Public Health 2017;27:318-324.

14. Nayagam S, Thursz M, Sicuri E, et al. Requirements for global elimination of hepatitis B: a modelling study. Lancet Infect Dis 2016;16:1399-1408.

15. Touloumi G, Karakosta A, Kaskafetou S, et al; Hprolipsis study group. Treatment cascade of hepatitis $\mathrm{B}$ and $\mathrm{C}$ in general, migrant and Roma populations. J Hepatology 2017;66(Suppl 1):S71-S72.

16. European Association for the Study of the Liver. EASL 2017 Clinical Practice Guidelines on the management of hepatitis B virus infection. J Hepatol 2017;67:370-398.

17. Dalekos GN, Goulis I, Manolakopoulos S, Papaevangelou V, Papatheodoridis GV; on behalf of the viral hepatitis scientific committee of the National Public Health Organization of Greece. Clinical practice guidelines on the management of hepatitis B virus infection. Available from: https://eody.gov.gr/wp-content/uploads/2019/01/Odigies-HBV2017-final.pdf [Accessed 16 February 2021].

18. European Association for the Study of the Liver. EASL Clinical Practice Guidelines: Management of hepatocellular carcinoma. J Hepatol 2018;69:182-236.

19. Zervou EK, Gatselis NK, Xanthi E, Ziciadis K, Georgiadou SP, Dalekos GN. Intrafamilial spread of hepatitis B virus infection in Greece. Eur J Gastroenterol Hepatol 2005;17:911-915.

20. Hassan MM, Hwang LY, Hatten CJ, et al. Risk factors for hepatocellular carcinoma: synergism of alcohol with viral hepatitis and diabetes mellitus. Hepatology 2002;36:1206-1213.

21. Shiomi S, Kuroki T, Minamitani S, et al. Effect of drinking on the outcome of cirrhosis in patients with hepatitis B or C. J Gastroenterol Hepatol 1992;7:274-276.

22. Larkin J, Clayton MM, Liu J, Feitelson MA. Chronic ethanol consumption stimulates hepatitis B virus gene expression and replication in transgenic mice. Hepatology 2001;34:792-797.

23. Dalekos GN, Zervou E, Karabini F, Tsianos EV. Prevalence of viral markers among refugees from southern Albania: increased incidence of infection with hepatitis A, B and D viruses. Eur J Gastroenterol Hepatol 1995;7:553-558.

24. Milionis C. Serological markers of Hepatitis B and C among juvenile immigrants from Albania settled in Greece. Eur J Gen Pract 2010;16:236-240.

25. Papoutselis KM, Kotsiou SS, Zacharakis G, et al. Epidemiology of hepatitis $\mathrm{B}$ and $\mathrm{C}$ viral infections in minorities of Thrace: Immigrants from the former USSR and moslem religious minority in relation to the general population of Thrace. J Hepatol 2001;34(Suppl 1):175-176.

26. Cooke GS, Andrieux-Meyer I, Applegate TL, et al; Lancet Gastroenterology \& Hepatology Commissioners. Accelerating the elimination of viral hepatitis: a Lancet Gastroenterology \& Hepatology Commission. Lancet Gastroenterol Hepatol 2019;4: 135-184.

27. Gatselis NK, Rigopoulou E, Stefos A, Kardasi M, Dalekos GN. Risk factors associated with HCV infection in semi-rural areas of central Greece. Eur J Intern Med 2007;18:48-55.

28. Gatselis NK, Zachou K, Lygoura V, et al. Geoepidemiology, clinical manifestations and outcome of primary biliary cholangitis in Greece. Eur J Intern Med 2017;42:81-88.

29. Chang TT, Liaw YF, Wu SS, et al. Long-term entecavir therapy results in the reversal of fibrosis/cirrhosis and continued histological improvement in patients with chronic hepatitis B. Hepatology 2010;52:886-893.

30. Papatheodoridis GV, Manolakopoulos S, Touloumi G, et al. Hepatocellular carcinoma risk in HBeAg-negative chronic hepatitis $B$ patients with or without cirrhosis treated with entecavir: HepNet. Greece cohort. J Viral Hepat 2015;22:120-127.

31. Vourli G, Papatheodoridis G, Raptopoulou M, et al. Association of antiviral therapy with reduced disease progression in chronic hepatitis B patients: Results from a nation-wide cohort study. Hippokratia 2016;20:214-221.

32. Lok AS, McMahon BJ, Brown RS Jr, et al. Antiviral therapy for chronic hepatitis B viral infection in adults: a systematic review and meta-analysis. Hepatology 2016;63:284-306.

33. Papatheodoridis GV, Dalekos GN, Yurdaydin C, et al. Incidence and predictors of hepatocellular carcinoma in Caucasian chronic hepatitis B patients receiving entecavir or tenofovir. $J$ Hepatol 2015;62:363-370.

34. Papatheodoridis G, Dalekos G, Sypsa V, et al. PAGE-B predicts the risk of developing hepatocellular carcinoma in Caucasians with chronic hepatitis B on 5-year antiviral therapy. J Hepatol 2016;64:800-806.

35. Papatheodoridis GV, Idilman R, Dalekos GN, et al. The risk of hepatocellular carcinoma decreases after the first 5 years of entecavir or tenofovir in Caucasians with chronic hepatitis B. Hepatology 2017;66:1444-1453.

36. Papatheodoridis GV, Sypsa V, Dalekos G, et al. Eight-year survival in chronic hepatitis $\mathrm{B}$ patients under long-term entecavir or tenofovir therapy is similar to the general population. $J$ Hepatol 2018;68:1129-1136.

37. Papatheodoridis GV, Sypsa V, Dalekos GN, et al. Hepatocellular carcinoma prediction beyond year 5 of oral therapy in a large cohort of Caucasian patients with chronic hepatitis B. J Hepatol 2020;72:1088-1096. 